\title{
TWO NEW CENOZOIC MICROTINE RODENTS
}

Claude W. Hibbard

Reprinted from Journal of Mammalogy

Vol. 38, Ns. 1, February, 1957

$$
\text { pp. 39-44 }
$$

Made in United States of America 

Made in United States of America

Reprinted from Jourval of MAMMalogy Vol. 38, No. 1, February, 1957

pp. $39-44$

TWO NEW CENOZOIC MICROTINE RODENTS

Claude W. Hubbard 
TWO NEW CENOZOIC MICROTINE RODENTS

\section{By Claude W. Hibbard}

Further washing of matrix from the Saw Rock Canyon local fauna locality in southwestern Kansas has produced numerous parts of a vole previously reported as Cosomys. Sufficient material has been found to show that the vole is distinct from Cosomys. It is here reported as a new species of the Pliocene genus Ogmodontomys. A lower jaw of a small vole from the early Pleistocene Sand Draw local fauna of Nebraska is described as a new genus and species.

Ogmodontomys sawrockensis sp. nov.

(Figs. 1A-F, 2C-I)

Cosomys primus Wilson, Hibbard, 1949. Contrib. Mus. Paleo., Univ. Mich., vol. 7 , no. 5, p. 103, fig. 2C-E.

Cosomys primus Wilson, Hibbard, 1953. Pap. Mich. Acad. Sci. Arts and Letters, vol. 38 (1952), p. 406.

Holotype.-No. 28166, University of Michigan Museum of Paleontology, part of the palatal region, which is broken just anterior to the posterior border of the incisive (anteropalatine) foramina and just posterior to the posterior palatine foramina. Only $\mathrm{RM}^{1}$ is present. Collected in the summer of 1951 , by the University of Michigan field party. 

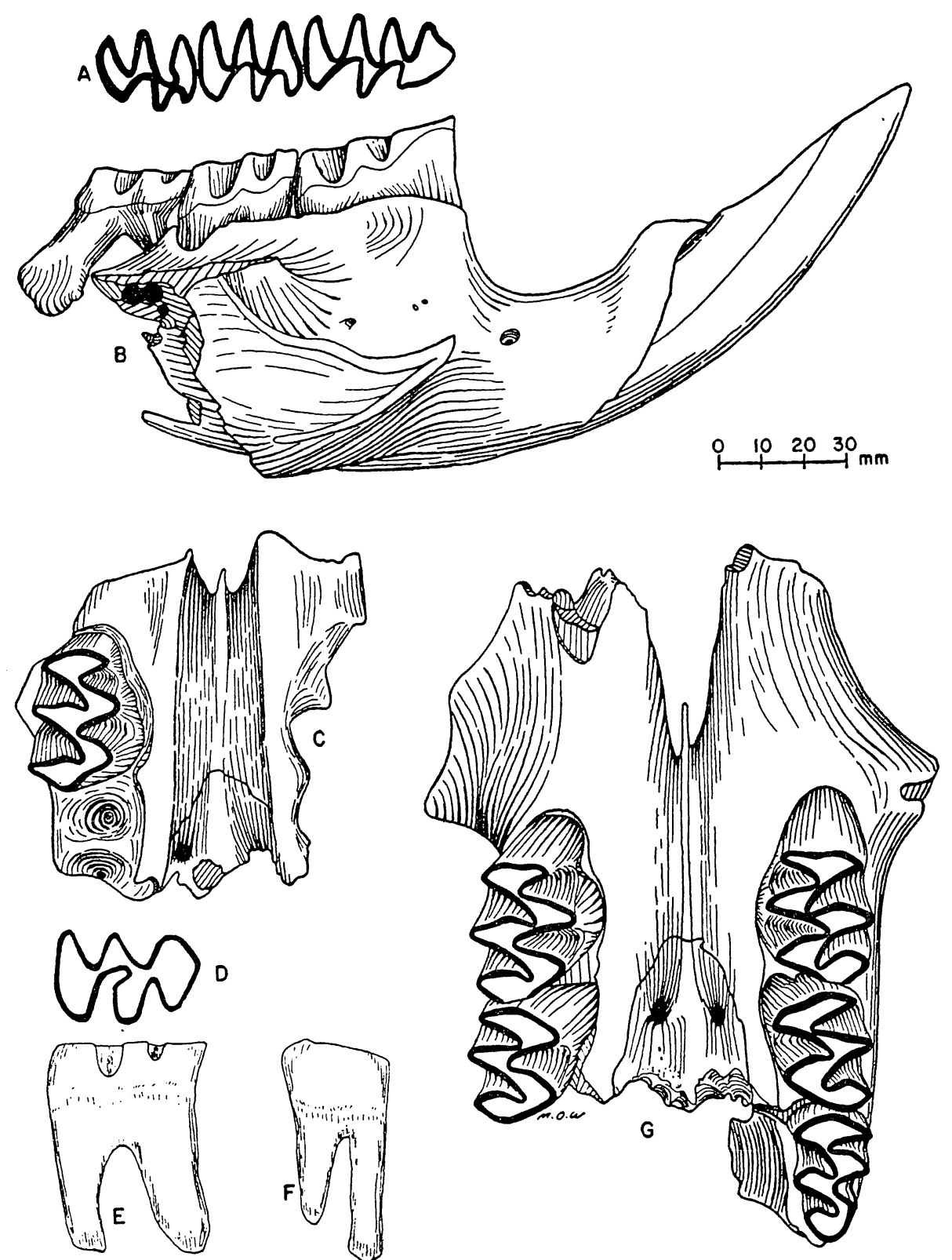

Frg. 1. - (A-F) Ogmodontomys sawrockensis sp. nov. (A and B) Occlusal view of $\mathrm{RM}_{1-}$ $\mathrm{M}_{3}$, and lateral view of right ramus, paratype UMMP No. 29715. (C) Ventral view of palate with $\mathrm{RM}^{1}$, holotype, UMMP No. 28166. All $\times 6$. (D, E and F) Occlusal, lingual and anterior views of $L^{3}{ }^{3}$, No. 33654a. $\times 8$. (G) Ventral view of palate with $\mathrm{RM}^{1}$ and $\mathrm{M}^{2}$, and $\mathrm{LM}^{1}-\mathrm{M}^{3}$, of Ogmodontomys poaphagus. $\times 6$. Drawing by Michael 0 . Woodburne. 
Paratypes.-No. 24344, is part of left lower jaw with $\mathrm{M}_{1}-\mathrm{M}_{2}$, and three isolated lower first molars; No. 29715, a fragmentary left lower jaw with incisor, $\mathrm{M}_{1}-\mathrm{M}_{3}$; No. 29716, parts of two right maxillaries, and a left maxillary with $\mathrm{M}^{1}$ and $\mathrm{M}^{2}$; No. 31013, part of a left lower jaw with $\mathrm{M}_{1}$ and $\mathrm{M}_{2}$ (Figs. $2 \mathrm{C}$ and $\mathrm{D}$ ); No. 33653, numerous isolated upper and lower teeth; No. 33654, three left upper third molars and part of an upper incisor.

Horizon and type locality.-Lower Upper Pliocene, XI member of the Rexroad formation, Saw Rock Canyon, sec. 36, T. 34 S., R. 31 W., Seward County, Kansas.

Diagnosis.-Slightly smaller than Ogmodontomys poaphagus Hibbard with shorter crowned teeth. The lateral palatal grooves are distinctly deeper than those of O. poaphagus.

Description of holotype.-The lateral palatal grooves extend posteriorly from each of the incisive foramina to a point opposite the middle of $\mathrm{M}^{2}$. The lateral palatal grooves are deep, especially in the anterior region of the palate, where they enter the incisive foramina (Fig. IC). The maxillary forming the outer wall of each groove is vertical, not sloping upward and outward to the alveolar plane as in Ogmodontomys poaphagus (Fig. 1G). The shape of the outer walls of the lateral grooves is more like the condition observed in Pliophenacomys primaevus Hibbard, and the subgenus Cosomys primus Wilson from the Hagerman local fauna of Idaho. The maxillary part of the bony septum separating the incisive foramina is more pronounced and extends more ventrally than in either C. primus or O. poaphagus. The bony septum extends posteriorly as a distinct median ridge on the ventral side of the maxillaries and the anterior part of the palatine. This median ridge separates the posterior palatine foramina. These foramina are large. They are approximately twice as large as those of $C$. primus. The distance from the posterior edge of the right incisive foramen to the anterior edge of the right palatine foramen is 4.75 $\mathrm{mm}$. The narrowest distance between the alveolar borders of the left and right $\mathrm{M}^{2}$ is $2.5 \mathrm{~mm}$. The anteroposterior length of $\mathrm{M}^{1}$ is $2.65 \mathrm{~mm}$. The right $\mathrm{M}^{1}$ consists of an anterior loop and four alternating triangles.

Description of paratypes.-Numerous isolated teeth have been recovered. The upper molars have three well-developed roots. Each lower molar has two roots. The three-rooted condition of $\mathrm{M}^{3}$ (Figs. $1 \mathrm{E}$ and $\mathrm{F} ; 2 \mathrm{~F}$ and $\mathrm{G}$ ) distinguishes it from Mimomys (Cosomys) primus which has only two roots. Some of the first upper molars have the enamel at the base of the crown on the front of the tooth developed into a prominent shelf (Figs. $2 \mathrm{H}$ and I). The upper incisor has a shallow groove along the outer edge of the tooth.

The mental foramen is on the labial side of the lower jaw anterior to the root of $M_{1}$ and just anterior to the masseteric crest (Figs. IB and 2D). There are parts of seven lower jaws with $M_{1}$ showing the position of the mental foramen. Its position is the same in all specimens regardless of stage of tooth wear. In Ogmodontomys poaphagus the mental foramen is more dorsally placed in some young and young adult specimens. The forward part of the ascending ramus leaves the jaw just opposite the last labial re-entrant angle of $M_{1}$. The 

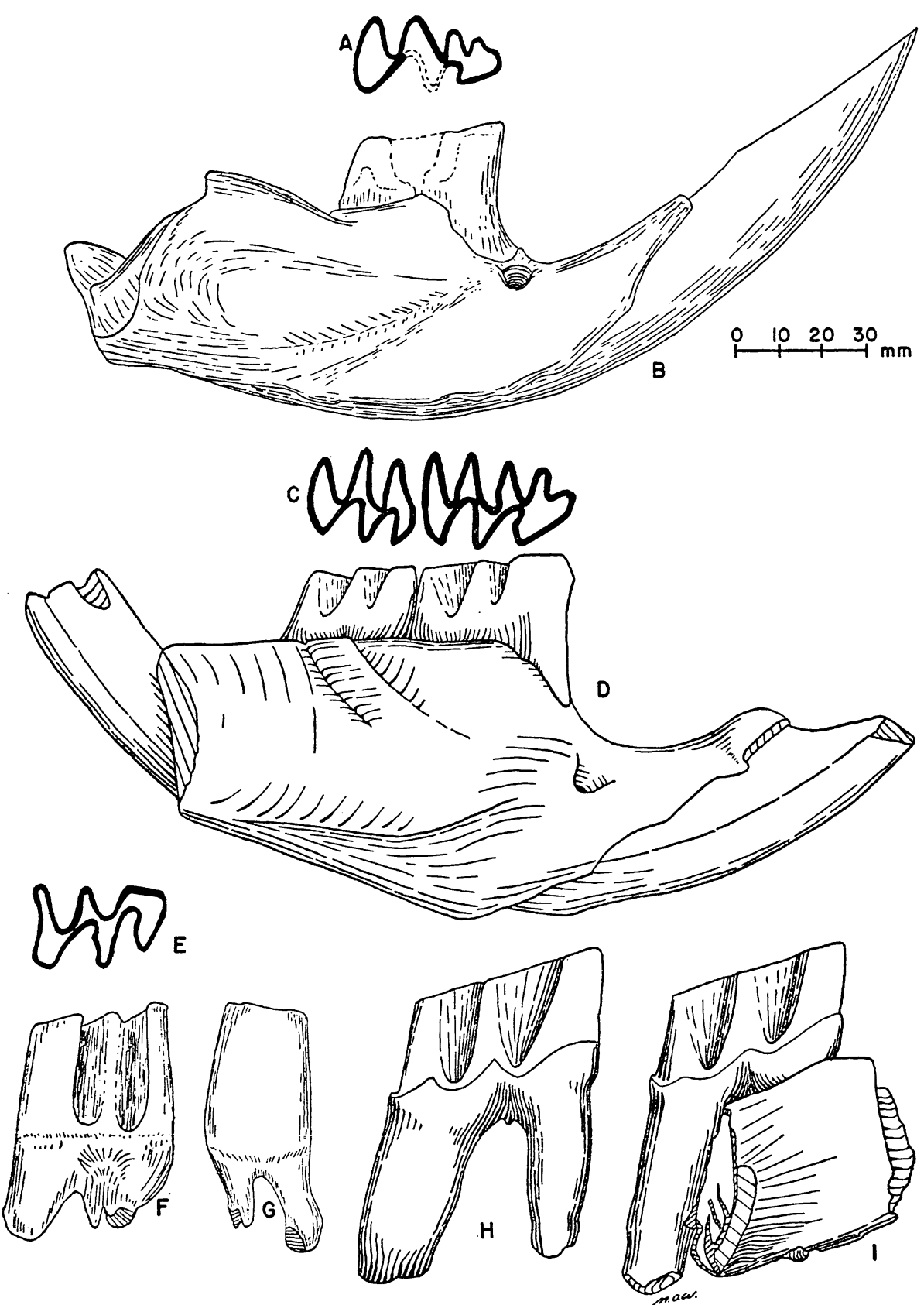

Fig. 2. - (A and B) Occlusal view of $\mathrm{RM}_{1}$, and lateral view of right ramus of Nebraskomys mcgrewi gen. and sp. nov.; holotype UMMP No. 25610. $\times$ 8. (C-I) Ogmodontomys sawrockensis sp. nov. ( $C$ and $D$ ) Occlusal view of $\mathrm{RM}_{1}$ and $\mathrm{M}_{2}$ and lateral view of right ramus, UMMP No. 31013. $\times 6$. (E, F and G) Occlusal, lingual and anterior views of LM ${ }^{3}$, UMMP No. $33654 \mathrm{~b} . \times 8$. $\left(\mathrm{H}\right.$ and I) Labial views of $\mathrm{RM}^{1}$, UMMP, No. 33653a-b. $\times 8$. Drawing by Michael O. Woodburne. 
anterior part of the lower jaw labial to the rest of $M_{1}$ is more slender than in O. poaphagus.

The reentrant angles of the upper and lower teeth are broad. The apex of the reentrant angles of the lower molars form, in most cases, a right angle to the longitudinal axis of the tooth. In Mimomys (Cosomys) primus the apex of the reentrant angle is directed forward and the enamel of the teeth is much thinner.

Specimen No. 29715 is the anterior part of a lower jaw (Figs. 1A and B) with incisor and $M_{1}-M_{3}$. The teeth are slightly narrower than those of $O$. poaphagus. The occlusal length of $\mathrm{M}_{1}-\mathrm{M}_{3}$ is $7.25 \mathrm{~mm}$.

A complete palate of this form is needed to determine its true relationship to the other fossil microtines.

Nebraskomys gen. nov.

Genotype.-Nebraskomys mcgrewi, sp. nov.

Diagnosis.-Nebraskomys is a vole, with rooted teeth, smaller than Pliophenacomys meadensis Hibbard and Pliolemmus antiquus Hibbard. The mental foramen is located just anterior to the anterior root of $\mathrm{M}_{1}$ and near the dorsal surface of the diastemal region. The incisor passes from the lingual side to the labial side of the jaw beneath the anterior root of $\mathrm{M}_{2}$.

\section{Nebraskomys megrewi sp. nov.}

(Figs. 2A and B)

Holotype.-No. 25610, University of Michigan Museum of Paleontology, is part of a right lower jaw with incisor, $\mathrm{M}_{1}$ and alveoli of $\mathrm{M}_{2}$. Collected in the summer of 1948 by Claude W. Hibbard and party.

Horizon and type locality.-Lower Pleistocene, late Nebraskan, from bed no. 4 (sand and clay of McGrew, 1944, p. 34, Geol. Ser. Field Mus. Nat. Hist. vol. 9, no. 2) taken in association with Geomys quinni McGrew, from the Sand Draw local fauna, six miles north of Ainsworth, near the center of the $\mathrm{W}^{1} 12 \mathrm{sec}$. 25, T. 31 N., R. 22 W., Brown County, Nebraska.

Description of holotype.-The lower jaw is that of an old adult. It is broken posterior to the alveoli of $\mathrm{M}_{2}$. The incisor is smaller than that of Pliophenacomys or Pliolemmus. There appears to have been no pit between $\mathrm{M}_{3}$ and the ascending ramus. The anterior part of the ascending ramus branches off opposite the posterior loop of $\mathrm{M}_{1}$, which is more posterior than in Ogmodontomys, Cosomys, and Pliophenacomys.

The enamel of $M_{1}$ is thick and uniform. The posterior loop is closed off from the first alternating triangle. The first and second triangles are confluent, a condition which may be due to the stage of wear. The apex of the second triangle is missing. The second triangle is closed off from the third. The third triangle is confluent with the anterior loop. The anterior loop is the shape of that loop in Ogmodontomys and the subgenus Cosomys.

This species is named for Dr. Paul O. McGrew, who previously studied the Sand Draw local fauna.

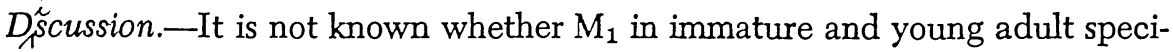


mens contained three or five alternating triangles. It has not been possible to remove a quantity of matrix for washing, which without doubt would add many small forms to the Sand Draw fauna. A tooth of Pliopotamys (Hibbard, 1956, p. 167, fig. 5G, Pap. Mich. Acad. Sci. Arts and Letters, vol. 41), was recovered at this locality when we were washing matrix for mollusks (Taylor, 1954, p. 14, Pap. Mus. Zool. Univ. Mich. no. 557).

The late Nebraskan age assigned to the Sand Draw fauna applies to the invertebrates and vertebrates coming from below bed no. 3 of McGrew. The overlying sand and gravel may be of Kansan age.

Museum of Paleontology, University of Michigan. Received June 30, 1956. 

